\title{
Analisis Faktor-Faktor yang Mempengaruhi Niat untuk Menggunakan Mobile Payment pada Masyarakat Kota Batam
}

\author{
Dewi Khornida Marheni \\ Universitas Internasional Batam \\ dewi@uib.ac.id \\ Gracia Melani \\ Universitas Internasional Batam \\ $\underline{1741053 . g r a c i a @ \text { uib.edu }}$
}

\begin{abstract}
Abstrak Mobile payment sebagai sistem pembayaran baru dengan teknologi membuat calon pengguna mempertimbangkan berbagai faktor sebelum berniat menggunakan. Penelitian bertujuan untuk mengetahui apakah faktor-faktor berupa persepsi biaya, persepsi resiko keuangan, usia, persepsi kemudahan penggunaan, dan persepsi keamanan mempengaruhi niat menggunakan mobile payment. Sebanyak 414 responden masyarakat Kota Batam digunakan sebagai subjek penelitian melalui penyebaran kuesioner. Penelitian menggunakan pendekatan kuantitatif dengan pengujian data primer melalui SEM-PLS. Hasil menunjukkan bahwa resiko keuangan, keamanan, serta kemudahan penggunaan menjadi faktor penentu niat penggunaan mobile payment. Namun, persepsi biaya tidak ditemukan hubungan yang signifikan. Usia juga tidak ditemukan hubungan yang signifikan terhadap kemudahan penggunaan mobile payment.
\end{abstract}

Kata Kunci Mobile Payment, Niat untuk Menggunakan, Fintech, Cashless

\section{PENDAHULUAN}

Seiring dengan berkembang pesatnya teknologi, teknologi finansial atau yang biasa disebut dengan fintech ini turut mengalami perkembangan yang signifikan. Berkembangnya fintech terutama fintech pembayaran sangat terasa dalam beberapa tahun terakhir. Berdasarkan data statistik Bank Indonesia, total jumlah volume transaksi pembayaran digital pada tahun 2019 adalah 5,2 miliar transaksi yang meningkat dari tahun 2018 dengan total transaksi sebesar 2,9 miliar. Sedangkan nilai transaksi pembayaran digital pada tahun 2018 meningkat dari Rp21,73 triliun menjadi Rp145,16 triliun pada tahun 2019. Dari data ini dapat diketahui bahwa terjadi peningkatan yang tajam pada nilai transaksi pembayaran digital tahun 2019 yaitu sebesar $207 \%$ dari tahun sebelumnya (bi.go.id). Data-data tersebut cukup membuktikan bahwa dalam satu tahun terakhir, fintech pembayaran mengalami perkembangan yang cukup signifikan dan berhasil mengumpulkan pengguna-pengguna baru dilihat dari meningkatnya jumlah transaksi fintech.

Dewasa ini masyarakat mulai berpaling dari transaksi konvensional menggunakan uang tunai menjadi transaksi digital menggunakan online payment atau digital payment, khususnya mobile payment. Hal ini dipicu oleh berkembangnya transaksi 
online atau e-commerce yang menawarkan produk dan jasa yang lebih beragam dengan harga yang relatif lebih murah. E-commerce tersebut diakses melalui sebuah aplikasi dan segala transaksi pembayaran dilakukan secara online. Mengetahui pergeseran perilaku transaksi dari offline menuju online ini, banyak perusahaan fintech bermunculan untuk menawarkan jasa keuangan, salah satunya jasa pembayaran.

Fintech pembayaran digital adalah salah satu jenis fintech yang paling mendominasi jasa fintech. Transaksi pembayaran digital ini sebagian besar dilakukan melalui smartphone, yang mana kegiatan ini disebut mobile payment. Mobile payment ini dinilai mudah dan praktis karena transaksi dilakukan hanya melalui smartphone, tidak seperti cara konvensional yang harus mendatangi kantor cabang bank untuk melakukan transaksi yang tentunya memakan waktu. Dengan adanya mobile payment, pengguna tidak perlu lagi membawa dan menggunakan uang tunai karena tanpa uang tunai transaksi dapat tetap berjalan. Berikut merupakan jumlah pengguna dari beberapa aplikasi mobile payment yang banyak digunakan di Indonesia.

Tabel 1 Jumlah Pengguna Aplikasi Mobile Payment

\begin{tabular}{lll}
\hline No & Nama Aplikasi & Jumlah Pengguna \\
\hline 1 & GO-PAY & 142 Juta (per Juli 2019) \\
2 & OVO & 80 Juta (per Januari 2020) \\
3 & LINKAJA & 61 Juta (per Januari 2021) \\
4 & DANA & 40 Juta (per April 2020) \\
5 & JENIUS & 2,4 Juta (per Desember 2019) \\
\hline
\end{tabular}

Sumber : katadata.co.id (2019), tirto.id (2020), rm.id (2020), money.kompas.com (2020), voi.id (2020).

Aplikasi pembayaran digital atau digital payment seperti GO-PAY, OVO, DANA, dan aplikasi lainnya telah memasuki pasar Kota Batam. Namun karena berbagai macam faktor, masyarakat di Batam masih belum sepenuhnya mendukung penggunaan sistem ini. Masyarakat Batam cenderung masih menggunakan pembayaran secara konvensional menggunakan uang tunai dalam bertransaksi dibanding menggunakan aplikasi digital payment. Pada penelitian oleh Teo et al. (2012), meneliti tentang pengaruh faktor demografi usia terhadap persepsi kemudahan penggunaan. Faktor-faktor demografi terutama usia, dapat menjadi faktor pengaruh niat seseorang untuk menggunakan fintech, didorong oleh adanya kemudahan dalam pengoperasian sebuah fintech.

Penggunaan mobile payment juga tidak luput dari biaya. Beberapa mobile payment membebankan biaya operasionalnya kepada pengguna, misalnya biaya pada setiap transaksi. Tidak hanya itu, beberapa mobile payment juga mengenakan biaya administrasi seperti saat melakukan pengisian top-up dana, penarikan dana, maupun transfer dana. Tentunya hal ini merugikan pengguna. Penggunaan mobile payment terkadang perlu memasukkan informasi tentang kartu kredit atau kartu debit dan juga menghubungkan akun pengguna pada aplikasi tersebut dengan kartu kredit atau kartu debit. Apalagi karena transaksi dilakukan secara online, hal ini membuat beberapa pengguna ataupun calon pengguna merasa khawatir akan resiko keuangan yang dapat terjadi, seperti penyalahgunaan dan pencurian akun/identitas yang dapat menimbulkan kerugian finansial, atau terdapat error pada aplikasi yang dapat mengakibatkan kehilangan uang. Sebuah fintech tidak luput dari ancaman resiko. Sebelum menggunakan fintech, calon pengguna akan memikirkan keamanan dan resiko kerugian yang bisa terjadi dalam penggunaannya. Untuk mendapatkan kepercayaan dari pengguna dan calon pengguna, 
pihak pengembang perlu meminimalisir resiko dengan meningkatkan keamanan fintechnya. Jika keamanan fintech terjaga, maka calon pengguna akan termotivasi untuk menggunakan fintech.

\section{LANDASAN TEORI}

Biaya merupakan salah satu faktor yang mempengaruhi keputusan seseorang dalam mengadopsi mobile payment. Ketika pengguna ingin menggunakan mobile payment, mereka harus membayar biaya tambahan, seperti smartphone, komunikasi nirkabel, dan layanan. Pengguna akan mengevaluasi biaya ini, jika biaya ini melebihi ekspektasi, pengguna akan menganggap bahwa menggunakan mobile payment tidak hemat biaya. Semakin mahal suatu layanan mobile payment dirasakan pengguna, semakin kecil keinginan mereka untuk menggunakannya (Liu et al., 2019).

Pada penelitian oleh Lema (2017), ditemukan bahwa niat pengguna mobile payment untuk mengadopsi dan menggunakan layanan keuangan seluler dipengaruhi secara negatif oleh biaya akses. Penelitian ini menunjukkan bahwa peningkatan biaya layanan keuangan seluler dapat menjadi penghalang untuk adopsi layanan keuangan seluler. Temuan ini sejalan dengan penelitian-penelitian oleh Busu et al. (2018) dan Liu et al. (2019). Sebaliknya Abrahão et al. (2016) serta Singh dan Sinha (2020) menemukan bahwa biaya tidak berpengaruh signifikan.

Penelitian oleh Ma et al. (2018) menemukan bahwa resiko keuangan memiliki efek negatif pada niat pengguna untuk menggunakan mobile payment, dikarenakan ketika pengguna merasakan adanya resiko kerugian finansial pada penggunaan mobile payment, niat pengguna untuk menggunakan mobile payment tersebut akan melemah. Ini mendukung hasil beberapa studi termasuk penelitian oleh Zhao et al. (2019).

Usia berhubungan kuat dengan adopsi teknologi baru. Secara umum, orang pada usia lanjut ditemukan kurang tertarik pada inovasi teknologi (Teo et al., 2012). Sedangkan, kaum muda atau lulusan universitas cenderung tidak memiliki masalah dalam penggunaan atau navigasi ponsel untuk layanan m-banking. Oleh karena itu, kaum muda dan yang berpendidikan tinggi mungkin tidak memiliki masalah dalam merasakan kemudahan penggunaan layanan $m$-banking (Teo et al., 2012).

Persepsi kemudahan penggunaan mengacu pada persepsi individu bahwa menggunakan sistem tertentu merupakan suatu hal yang mudah, sederhana, dan mudah ditangani (Taylor dan Todd, 1995). Oleh karena itu, persepsi kemudahan penggunaan dianggap sebagai salah satu aspek yang paling berpengaruh terhadap keputusan untuk menggunakan teknologi baru (Ramos de Luna et al., 2019). Mengingat bahwa layanan mobile payment merupakan alternatif dari metode pembayaran yang sudah tertanam seperti kartu kredit, kartu debit, uang tunai, dan cek, penting bahwa konsumen memandang layanan mobile payment sebagai paling tidak sebuah layanan yang mudah digunakan seperti metode-metode sebelumnya. Jika layanan mobile payment membutuhkan usaha yang signifikan dari konsumen, maka akan menjadi penghalang untuk mengadopsi (Johnson et al., 2018). Jika pengguna berpikir bahwa belajar menggunakan mobile payment itu mudah dan bahwa proses operasinya sederhana, maka persepsi mereka tentang kegunaan mobile payment akan meningkat dan mereka akan lebih cenderung mengadopsi teknologi ini (Liu et al., 2019).

Salah satu hambatan terbesar untuk menggunakan layanan mobile payment adalah kekhawatiran terhadap keamanan (Slade et al., 2016). Masuk akal untuk percaya bahwa semakin konsumen percaya akan keamanan layanan mobile payment, semakin besar kemungkinan mereka akan mengadopsi teknologi (Johnson et al., 2018). Masalah 
keamanan merupakan faktor yang memengaruhi adopsi layanan mobile payment. Meskipun penyedia layanan menganggap layanan mobile payment lebih aman daripada layanan pembayaran tradisional seperti pembayaran kartu kredit dan debit, pelanggaran keamanan tingkat tinggi baru-baru ini mungkin membuat konsumen waspada menggunakan teknologi pembayaran baru (Johnson et al., 2018). Jika konsumen merasakan adanya keamanan yang tinggi pada mobile payment tersebut, konsumen akan menunjukkan kecenderungan yang lebih besar untuk menerima dan mengadopsi sistem mobile payment. Persepsi keamanan konsumen memang merupakan faktor penting yang harus selalu ditangani sejak awal ketika merancang strategi untuk penerapan sistem pembayaran baru (Ramos-de-Luna et al., 2017).

Penelitian ini menggunakan model penelitian dengan mengambil dan menggabungkan konstruksi-konstruksi dari penelitian-penelitian terdahulu. Berikut ini merupakan model hubungan antara variabel dependen dan variabel independen dari penelitian ini.

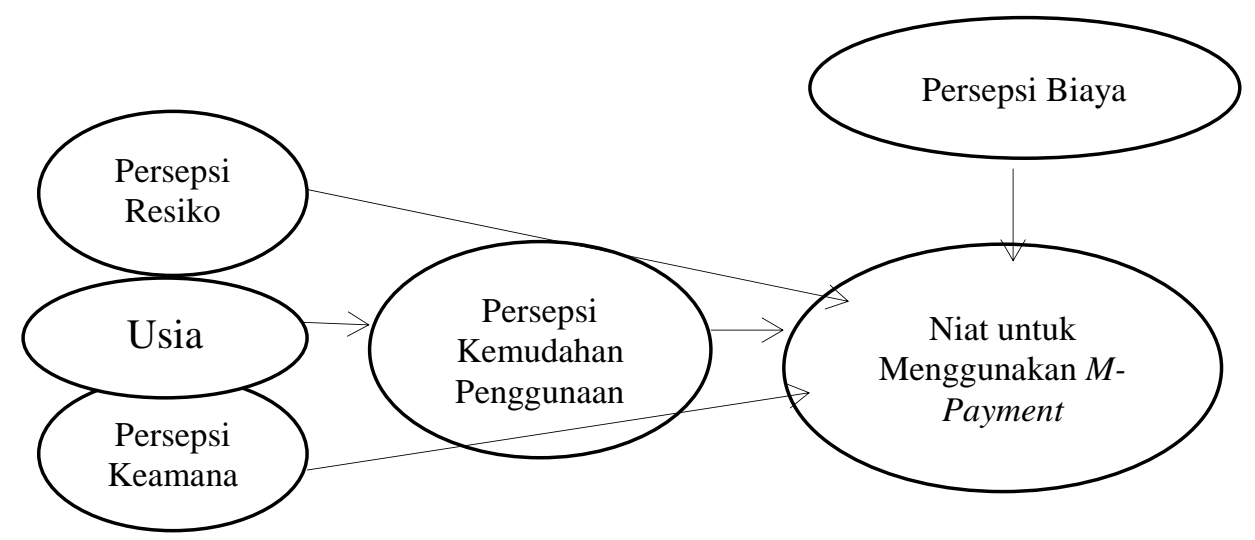

Gambar 1. Model Penelitian Niat untuk Menggunakan Mobile Payment

Berdasarkan model penelitian diatas dapat dirumuskan hipotesis dari penelitian ini.

$H_{1}$ : Persepsi biaya (perceived cost) memiliki pengaruh signifikan negatif terhadap niat untuk menggunakan layanan mobile payment (intention to use).

$\mathrm{H}_{2}$ : Persepsi resiko keuangan (perceived financial risk) berpengaruh signifikan negatif terhadap niat untuk menggunakan layanan mobile payment (intention to use).

$H_{3}$ : Usia berpengaruh signifikan negatif terhadap persepsi kemudahan penggunaan (perceived ease of use).

$H_{4}$ : Persepsi kemudahan penggunaan (perceived ease of use) berpengaruh signifikan positif terhadap niat untuk menggunakan layanan mobile payment (intention to use).

$H_{5}$ : Persepsi keamanan (perceived security) berpengaruh signifikan positif terhadap niat untuk menggunakan layanan mobile payment (intention to use).

\section{METODOLOGI PENELITIAN Rancangan Penelitian}

Penelitian ini merupakan penelitian dasar yang dilakukan berdasarkan teori-teori serta penelitian-penelitian yang telah ada sebelumnya, dilihat dari tujuan penelitian yang telah dipaparkan sebelumnya. Metode analisis yang digunakan adalah PLS atau Partial Least Squares dilakukan dalam pengolahan data primer pada penelitian ini. Penelitian ini mengumpulkan responden dari masyarakat Kota Batam yang menggunakan mobile payment dan yang belum atau berpotensi menggunakan mobile payment. Tidak hanya 
ditujukan pada kalangan muda dan terpelajar, penelitian ini diharapkan dapat menjangkau kelompok usia yang lebih bervariasi, terutama kalangan ibu-ibu, bapak-bapak, dan yang sudah lanjut usia. Hal ini untuk mengetahui apakah terdapat pengaruh demografi berupa usia pada penelitian ini.

\section{HASIL PENELITIAN}

Penelitian ini menggunakan metode pengumpulan data survei dalam bentuk kuesioner yang dibagikan secara online melalui google form. Pengumpulan data dilakukan pada Maret 2020 hingga Oktober 2020 dan dibagikan kepada 414 responden.

Tabel 2 Data Statistik Responden

\begin{tabular}{ll}
\hline Keterangan & Jumlah Kuesioner \\
\hline Kuesioner yang di sebarkan & 414 \\
Kuesioner yang tidak di isi lengkap & 0 \\
Kuesioner yang tidak kembali & 0 \\
Kuesioner yang digunakan untuk analisis & 414 \\
\hline
\end{tabular}

Sumber : Data primer yang diolah (2020).

Untuk menguji validitas dari setiap konstruk pada penelitian ini, peneliti menerapkan pengujian AVE. Hasil pengujiannya dapat dilihat pada tabel berikut ini.

Tabel 9 Uji Average Variance Extracted

\begin{tabular}{lll}
\hline Pernyataan & Nilai AVE & Keterangan \\
\hline Niat Menggunakan Mobile Payment & 0,821 & Valid \\
Persepsi Biaya & 0,781 & Valid \\
Persepsi Keamanan & 0,694 & Valid \\
Persepsi Kemudahan Penggunaan & 0,690 & Valid \\
Persepsi Resiko Keuangan & 0,592 & Valid \\
\hline
\end{tabular}

Sumber : Data primer yang diolah (2020).

Hasil daripada tabel diatas maka dapat diambil kesimpulan bahwa semua variabel pada penelitian ini dinyatakan valid karena memiliki nilai AVE lebih dari 0,5 $(>0,5)$. Untuk menguji reliabilitas dari setiap konstruk pada penelitian ini, peneliti melakukan uji Composite Reliability. Hasil pengujiannya pada tabel berikut ini.

Tabel 11 Uji Composite Reliability

\begin{tabular}{lll}
\hline Pernyataan & $\begin{array}{l}\text { Nilai Composite } \\
\text { Reliability }\end{array}$ & Keterangan \\
\hline Niat Menggunakan Mobile Payment & 0,932 & Reliabel \\
Persepsi Biaya & 0,915 & Reliabel \\
Persepsi Keamanan & 0,919 & Reliabel \\
Persepsi Kemudahan Penggunaan & 0,917 & Reliabel \\
Persepsi Resiko Keuangan & 0,853 & Reliabel \\
\hline
\end{tabular}

Sumber : Data primer yang diolah (2020).

Dari hasil yang didapatkan ini dapat diambil kesimpulan bahwa semua variabel pada penelitian ini reliabel karena memiliki nilai Composite Reliability lebih dari 0,7 $(>0,7)$.Untuk mengetahui pengaruh variabel independent terhadap variabel dependen dilakukan uji Path Coefficients. Hasil pengujiannya dapat dilihat pada tabel berikut. 
Tabel 12 Uji Path Coefficients

\begin{tabular}{|c|c|c|c|c|c|}
\hline Jalur (X -> Y) & $\begin{array}{l}\text { Original } \\
\text { Sample }\end{array}$ & $\begin{array}{l}\text { Sample } \\
\text { Mean }\end{array}$ & T-Statitics & P Values & Hipotesis \\
\hline $\begin{array}{l}\text { Persepsi Biaya -> Niat } \\
\text { Menggunakan Mobile } \\
\text { Payment }\end{array}$ & 0,098 & 0,101 & 2,220 & 0,027 & $\begin{array}{l}\text { Tidak } \\
\text { berpengaruh } \\
\text { signifikan }\end{array}$ \\
\hline $\begin{array}{l}\text { Persepsi Keamanan -> } \\
\text { Niat Menggunakan } \\
\text { Mobile Payment }\end{array}$ & 0,191 & 0,187 & 3,857 & 0,000 & $\begin{array}{l}\text { Berpengaruh } \\
\text { signifikan positif }\end{array}$ \\
\hline $\begin{array}{l}\text { Persepsi Kemudahan } \\
\text { Penggunaan -> Niat } \\
\text { Menggunakan Mobile } \\
\text { Payment }\end{array}$ & 0,485 & 0,484 & 9,888 & 0,000 & $\begin{array}{l}\text { Berpengaruh } \\
\text { signifikan positif }\end{array}$ \\
\hline $\begin{array}{l}\text { Persepsi Resiko } \\
\text { Keuangan -> Niat } \\
\text { Menggunakan Mobile } \\
\text { Payment }\end{array}$ & $-0,118$ & $-0,121$ & 3,527 & 0,000 & $\begin{array}{l}\text { Berpengaruh } \\
\text { signifikan negatif }\end{array}$ \\
\hline $\begin{array}{l}\text { Usia -> Persepsi } \\
\text { Kemudahan } \\
\text { Penggunaan }\end{array}$ & $-0,017$ & $-0,016$ & 0,301 & 0,763 & $\begin{array}{l}\text { Tidak } \\
\text { berpengaruh } \\
\text { signifikan }\end{array}$ \\
\hline
\end{tabular}

Sumber : Data primer yang diolah (2020).

H1 : Persepsi biaya (perceived cost) memiliki pengaruh signifikan negatif terhadap niat untuk menggunakan layanan mobile payment (intention to use). (Ditolak)

$\mathrm{H} 2$ : Persepsi resiko keuangan (perceived financial risk) berpengaruh signifikan negatif terhadap niat untuk menggunakan layanan mobile payment (intention to use). (Diterima) H3 : Usia berpengaruh signifikan negatif terhadap persepsi kemudahan penggunaan (perceived ease of use). (Ditolak)

H4 : Persepsi kemudahan penggunaan (perceived ease of use) berpengaruh signifikan positif terhadap niat untuk menggunakan layanan mobile payment (intention to use). (Diterima)

H5 : Persepsi keamanan (perceived security) berpengaruh signifikan positif terhadap niat untuk menggunakan layanan mobile payment (intention to use). (Diterima)

Uji Koefisien Determinasi atau Adjusted $R^{2}$ ini dilakukan pada penelitian ini untuk mengetahui besar pengaruh yang diberikan variabel independen terhadap variabel dependen.

Tabel 13 Uji Adjusted $R^{2}$

\begin{tabular}{ll}
\hline Model & Adjusted R Square \\
\hline Niat Menggunakan Mobile Payment & 0,481 \\
Persepsi Kemudahan Penggunaan & 0,001 \\
\hline
\end{tabular}

Sumber : Data primer diolah (2020).

Dari tabel hasil pengujian diatas, variabel niat menggunakan mobile payment memiliki nilai adjusted $R^{2}$ sebesar 0,481 yang berarti variabel persepsi biaya, persepsi resiko keuangan, variabel demografi usia, persepsi kemudahan penggunaan, serta persepsi keamanan mempengaruhi variabel niat menggunakan mobile payment sebesar $48,1 \%$, sementara sisanya yaitu sebesar $42,9 \%$ dipengaruhi variabel lain yang tidak terdapat pada 
model. Kemudian variabel persepsi kemudahan penggunaan memiliki nilai adjusted $R^{2}$ sebesar 0,001 yang berarti variabel demografi usia mempengaruhi variabel persepsi kemudahan penggunaan sebesar $0,1 \%$ dan sisanya dipengaruhi oleh variabel lain.

\section{PEMBAHASAN}

Persepsi biaya ditemukan tidak memiliki pengaruh yang signifikan terhadap niat menggunakan mobile payment. Menurut peneliti ada beberapa alasan yang dapat menjelaskan hasil yang didapatkan ini. Mobile payment yang digunakan oleh masyarakat luas di Indonesia sudah tidak lagi membebankan biaya operasional serta biaya-biaya lain dalam jumlah besar kepada penggunanya. Biaya yang dibebankan oleh layanan mobile payment hanya berupa biaya top-up saldo yang memakan sekitar Rp 1.000 hingga Rp 2.000 per transaksi. Angka ini dianggap cukup murah dan tidak menjadi penghalang bagi pengguna dalam bertransaksi menggunakan layanan mobile payment.

Hasil pengujian ini didukung oleh beberapa penelitian yang telah dilakukan oleh Singh dan Sinha (2020), Yadav et al. (2020), Abrahão et al. (2016), Pham dan Ho (2015) yang menemukan bahwa tidak adanya pengaruh signifikan terhadap niat penggunaan mobile payment. Bisa diambil kesimpulan bahwa persepsi biaya bukan merupakan faktor penentu yang berpengaruh terhadap intensi penggunaan mobile payment. Temuan ini bertentangan dengan penelitian terdahulu yang dilakukan oleh Busu et al. (2018) dan Liu et al. (2019) yang menemukan adanya hubungan signifikan antara persepsi biaya dengan niat menggunakan mobile payment.

Persepsi resiko keuangan ditemukan memiliki pengaruh yang signifikan negatif terhadap niat menggunakan mobile payment. Menurut peneliti ada beberapa alasan yang dapat menjelaskan hasil yang didapatkan ini. Sebagian orang cenderung memandang jenis pembayaran cashless seperti mobile payment ini beresiko dan tidak terhindar dari ancaman kerugian finansial, karena baik penyimpanan dana berupa saldo maupun kegiatan transaksi tersebut dilakukan secara online. Calon pengguna tidak sepenuhnya yakin bahwa sewaktu-waktu tidak akan terjadi permasalahan yang dapat merugikan, seperti terungkapnya informasi rekening atau penipuan, saldo yang hilang atau terkuras misalnya karena penyalahgunaan, adanya error pada aplikasi atau smartphone, atau karena jaringan yang tidak mendukung dan tidak lancar saat melakukan transaksi. Semakin tinggi resiko keuangan yang dirasakan pengguna, maka niat untuk menggunakan mobile payment akan semakin rendah atau melemah.

Hasil pengujian ini didukung oleh beberapa penelitian yang telah dilakukan oleh Pauchard (2019), Reith et al. (2019), Zhao et al. (2019) dan Ma et al. (2018) yang menemukan bahwa adanya pengaruh signifikan negatif dari persepsi resiko keuangan terhadap niat penggunaan mobile payment. Bisa diambil kesimpulan bahwa persepsi resiko keuangan merupakan faktor penentu yang berpengaruh terhadap intensi penggunaan mobile payment.

variabel usia ditemukan tidak memiliki pengaruh yang signifikan terhadap persepsi kemudahan penggunaan. Menurut peneliti ada beberapa alasan yang dapat menjelaskan hasil yang didapatkan ini. Responden pada penelitian ini mayoritas merupakan pelajar atau mahasiswa yang termasuk kaum milenial, sehingga lebih mengikuti dan terbuka terhadap perkembangan teknologi. Oleh karena itu, para kaum milenial ini cenderung tidak menemukan adanya kesulitan dalam menggunakan teknologi seperti penggunaan sistem mobile payment.

Hasil pengujian ini didukung oleh penelitian Teo et al. (2012) yang menemukan bahwa tidak adanya pengaruh signifikan antara usia terhadap persepsi kemudahan 
penggunaan. Hal ini dikarenakan mayoritas responden pada penelitian tersebut merupakan kaum muda dan berpendidikan tinggi sehingga kemungkinan tidak memiliki masalah dalam penggunaan sistem. Bisa diambil kesimpulan bahwa pada penelitian ini variabel demografi usia bukan merupakan faktor penentu yang berpengaruh terhadap persepsi kemudahan penggunaan mobile payment. Temuan ini bertentangan dengan penelitian terdahulu yang dilakukan oleh Giovanis et al. (2012), Fiedler dan Öztüren (2014), dan Tingari dan Sanhori (2016) yang menemukan adanya hubungan yang signifikan negatif antara usia dengan persepsi kemudahan penggunaan.

persepsi kemudahan penggunaan ditemukan memiliki pengaruh yang signifikan positif terhadap niat menggunakan mobile payment. Menurut peneliti ada beberapa alasan yang dapat menjelaskan hasil yang didapatkan ini. Teknologi selalu mengalami perkembangan dan semakin banyak teknologi baru yang bermunculan. Namun terkadang teknologi ini tidak mudah untuk dioperasikan dan membutuhkan waktu untuk mempelajarinya. Calon pengguna tentu ingin penggunaan mobile payment tersebut agar mudah dan praktis, sehingga dengan adanya kemudahan penggunaan pada mobile payment, calon pengguna akan terdorong dan berkenan untuk menggunakannya.

Hasil pengujian ini didukung oleh beberapa penelitian yang telah dilakukan oleh Kabata (2015), Nguyen dan Huynh (2018), Johnson et al. (2018), Liu et al. (2019), Lau et al. (2019), Wong dan Mo (2019), serta Ziwei et al. (2019) yang menemukan bahwa adanya pengaruh signifikan positif dari persepsi kemudahan penggunaan terhadap niat penggunaan mobile payment. Bisa diambil kesimpulan bahwa persepsi kemudahan penggunaan merupakan faktor penentu yang secara positif berpengaruh terhadap intensi penggunaan mobile payment. Temuan ini bertentangan dengan penelitian terdahulu yang dilakukan oleh Denaputri dan Usman (2019) serta Phonthanukitithaworn et al. (2016) yang tidak menemukan adanya hubungan signifikan antara persepsi kemudahan penggunaan dengan niat menggunakan mobile payment.

Persepsi keamanan ditemukan memiliki pengaruh yang signifikan positif terhadap niat menggunakan mobile payment. Menurut peneliti ada beberapa alasan yang dapat menjelaskan hasil yang didapatkan ini. Keamanan sistem mobile payment mempengaruhi tingkat kepercayaan calon pengguna, sehingga semakin aman suatu sistem maka calon pengguna akan semakin bersedia untuk menggunakannya. Calon pengguna percaya jika mobile payment tersebut aman, segala informasi serta transaksi mereka akan terlindungi. Apalagi sistem layanan mobile payment ini berhubungan erat dengan keuangan, sehingga wajar bagi calon pengguna untuk menginginkan sebuah sistem yang aman untuk melakukan kegiatan transaksi.

Hasil pengujian ini didukung oleh beberapa penelitian yang telah dilakukan oleh Johnson et al. (2018), Musa et al. (2015), Ramos de Luna et al. (2019), Ramos de Luna et al. (2017), Liébana-Cabanillas et al. (2017), Tingari dan Sanhori (2016), Wong dan Mo (2019), Moorthy et al. (2020), Denaputri dan Usman (2019), serta Soodan dan Rana (2020) yang menemukan bahwa adanya pengaruh signifikan positif dari persepsi keamanan terhadap niat penggunaan mobile payment. Bisa diambil kesimpulan bahwa persepsi keamanan merupakan faktor penentu yang berpengaruh terhadap intensi penggunaan mobile payment. Temuan ini bertentangan dengan penelitian terdahulu yang dilakukan oleh Aydin (2016) dan Lau et al. (2019) yang tidak menemukan adanya hubungan signifikan antara persepsi keamanan dengan niat menggunakan mobile payment. 


\section{KESIMPULAN}

Berdasarkan hasil pengujian yang didapatkan pada bab sebelumnya, dapat ditarik kesimpulan bahwa variabel persepsi kemudahan penggunaan dan variabel persepsi keamanan berpengaruh signifikan positif niat konsumen dalam menggunakan mobile payment di Kota Batam.

\section{UCAPAN TERIMA KASIH}

Terima kasih kepada Universitas Internasional Batam (UIB), Rekan mahasiswa, dan Keluarga atas dukungan yang diberikan kepada penulis dalam menyelesaikan karya ilmiah ini. Semoga karya ilmiah ini bisa bermanfaat untuk masyarakat luas.

\section{DAFTAR PUSTAKA}

Abrahão, R. de S., Moriguchi, S. N., \& Andrade, D. F. (2016). Intention of adoption of mobile payment: An analysis in the light of the Unified Theory of Acceptance and Use of Technology (UTAUT). RAI Revista de Administração e Inovação, 13(3), 221-230. https://doi.org/10.1016/j.rai.2016.06.003

Aydin, G. (2016). Adoption of mobile payment systems: a study on mobile wallets. $\begin{array}{lll}\text { Pressacademia, 5(1), 73-73. } & \end{array}$ https://doi.org/10.17261/pressacademia.2016116555

Badan Pusat Statistik Kota Batam. (2019). Retrieved from www.batamkota.bps.go.id Bank Indonesia. (2019). Retrieved from bi.go.id

Busu, S., Karim, N. A., \& Haron, H. (2018). Factors of adoption intention for near field communication mobile payment. Indonesian Journal of Electrical Engineering and Computer $\quad$ Science, 11(1), 98-104. https://doi.org/10.11591/ijeecs.v11.i1.pp98-104

Davis, F. D., Bagozzi, R. P., \& Warshaw, P. R. (1989). User Acceptance of Computer Technology: A Comparison of Two Theoretical Models. Management Science, 35(8), 982-1003. https://doi.org/10.1287/mnsc.35.8.982

de Luna, I. R., Liébana-Cabanillas, F., Sánchez-Fernández, J., \& Muñoz-Leiva, F. (2019). Mobile payment is not all the same: The adoption of mobile payment systems depending on the technology applied. Technological Forecasting and Social Change, 146(October 2017), 931-944. https://doi.org/10.1016/j.techfore.2018.09.018

Denaputri, Annisa; Usman, O. (2019). Effect of Perceived Trust, Perceived Security, Perceived Usefulness and Perceived Ease of use on Customers' Intention to Use Mobile Payment. Harvard Business Review, 1.

Dwi. (2021). Sepanjang Pandemi, Pengguna LinkAja Capai 61 Juta Orang. Retrieved from https://rm.id/baca-berita/ekonomi-bisnis/60740/sepanjang-pandemipengguna-linkaja-capai-61-juta-orang

Fiedler, M., \& Öztüren, A. (2014). Online behavior and loyalty program participationparameters influencing the acceptance of contactless payment devices. Research Journal of Applied Sciences, Engineering and Technology, 7(15), 3188-3197. https://doi.org/10.19026/rjaset.7.660

Fitra, S. (2019). Perbankan dan Fintech Pembayaran, Bukan Lawan tapi Kawan. https://katadata.co.id/berita/2019/10/07/perbankan-dan-fintech-pembayaranbukan-lawan-tapi-kawan

Gana, K. C., Mathew, A. O., Joseph, J., Rodrigues, L. L. R., \& Sriram, K. V. (2018). An empirical study on customer adoption of mobile payment application in India. 
International Journal of Enterprise Network Management, 9(3/4), 363. https://doi.org/10.1504/ijenm.2018.10015851

Gia-Shie Liu, \& Pham Tan Tai. (2016). A Study of Factors Affecting the Intention to Use Mobile Payment Services in Vietnam. Economics World, 4(6), 249-273. https://doi.org/10.17265/2328-7144/2016.06.001

Giovanis, A. N., Binioris, S., \& Polychronopoulos, G. (2012). An extension of TAM model with IDT and security/privacy risk in the adoption of internet banking services in Greece. EuroMed Journal of Business, 7(1), 24-53. https://doi.org/10.1108/14502191211225365

Hair, J. F., Black, W. C., Babin, B. J., \& Anderson, R. E. (2014). Multivariate data analysis. In Pearson custom library. https://doi.org/10.1038/259433b0

Henseler, J., \& Sarstedt, M. (2013). Goodness-of-fit indices for partial least squares path modeling. Computational Statistics, 28(2), 565-580. https://doi.org/10.1007/s00180-012-0317-1

Jannah, S. M. (2020). Transaksi OVO Tembus 1 Miliar di Tahun 2019. Retrieved from https://tirto.id/transaksi-ovo-tembus-1-miliar-di-tahun-2019-eroV

Johnson, V. L., Kiser, A., Washington, R., \& Torres, R. (2018). Limitations to the rapid adoption of M-payment services: Understanding the impact of privacy risk on M-Payment services. Computers in Human Behavior, 79, 111-122. https://doi.org/10.1016/j.chb.2017.10.035

Kabata, D. (2015). Determinants of Mobile Payment Use by Consumers in Kenya. International Journal of Computer Applications \& Information Technology, 8(I), $8(\mathrm{I}), 152-159$.

Kurniawan, D. (2020). Pengguna Aplikasi Jenius Capai 2,4 Juta. Retrieved from https://voi.id/berita/3988/pengguna-aplikasi-jenius-capai-2-4-juta\#: :text=Tak hanya itu $\% 2 \mathrm{C}$ kredit juga, 8 persen dari tahun sebelumnya.

Lau, M. M., Lam, A. Y. C., Cheung, R., \& Leung, T. F. (2019). Understanding determinants of customer behavioral intention in using mobile payment at convenience stores. ACM International Conference Proceeding Series, 357-362. https://doi.org/10.1145/3306500.3306549

Lema, A. (2017). Factors influencing the adoption of mobile financial services in the unbanked population. Inkanyiso: Journal of Humanities and Social Sciences, 9(1), 37-51-51.

Liébana-Cabanillas, F., de Luna, I. R., \& Montoro-Ríosa, F. (2017). Intention to use new mobile payment systems: A comparative analysis of SMS and NFC payments. Economic Research-Ekonomska Istrazivanja 30(1), 892-910. https://doi.org/10.1080/1331677X.2017.1305784

Liu, Y., Wang, M., Huang, D., Huang, Q., Yang, H., \& Li, Z. (2019). The impact of mobility, risk, and cost on the users' intention to adopt mobile payments. Information Systems and E-Business Management, 17(2-4), 319-342. https://doi.org/10.1007/s10257-019-00449-0

Luarn, P., \& Lin, H. H. (2005). Toward an understanding of the behavioral intention to use mobile banking. Computers in Human Behavior, 21(6), 873-891. https://doi.org/10.1016/j.chb.2004.03.003

Ma, L., Su, X., Yu, Y., Wang, C., Lin, K., \& Lin, M. (2018). What Drives the Use of MPayment? An Empirical Study about Alipay and WeChat Payment. 2018 15th International Conference on Service Systems and Service Management, ICSSSM 2018, 71471118, 1-6. https://doi.org/10.1109/ICSSSM.2018.8465029 
Moorthy, K., Chun T'ing, L., Chea Yee, K., Wen Huey, A., Joe In, L., Chyi Feng, P., \& Jia Yi, T. (2020). What drives the adoption of mobile payment? A Malaysian perspective. International Journal of Finance and Economics, 25(3), 349-364. https://doi.org/10.1002/ijfe.1756

Musa, A., Khan, H. U., \& AlShare, K. A. (2015). Factors influence consumers' adoption of mobile payment devices in Qatar. International Journal of Mobile Communications, 13(6), 670-689. https://doi.org/10.1504/IJMC.2015.072100

Nguyen, T. D., \& Huynh, P. A. (2018). The roles of perceived risk and trust on E-payment adoption. Studies in Computational Intelligence, 760, 926-940. https://doi.org/10.1007/978-3-319-73150-6_68

Pauchard, L. (2019). A Comparison of the Different Types of Risk Perceived by Users that Are Hindering the Adoption of Mobile Payment. In Lecture Notes of the Institute for Computer Sciences, Social-Informatics and Telecommunications Engineering, LNICST (Vol. 285). Springer International Publishing. https://doi.org/10.1007/978-3-030-

Pham, T. T. T., \& Ho, J. C. (2015). The effects of product-related, personal-related factors and attractiveness of alternatives on consumer adoption of NFC-based mobile payments. Technology in Society, 43, 159-172. https://doi.org/10.1016/j.techsoc.2015.05.004

Phonthanukitithaworn, C., Sellitto, C., \& Fong, M. W. L. (2016). An investigation of mobile payment (mpayment) services in Thailand. Asia-Pacific Journal of Business Administration, 5(2). https://doi.org/http://dx.doi.org/10.1108/APJBA10-2014-0119

Pusparisa, Y. (2019). LinkAja, OVO, atau Go-Pay: Mana yang Anda Pilih? Retrieved from https://katadata.co.id/ariayudhistira/infografik/5e9a50d90e74e/linkajaovo-atau-go-pay-mana-yang-anda-pilih

PwC. (2016). Mobile Payment: Repräsentative Bevölkerungsumfrage 2016. Retrieved from https://www.pwc.de/de/digitale-transformation/assets/pwcbevoelkerungsbefragung-mobile- payment-2016.pdf

Ramos-de-Luna, I., Montoro-Ríos, F., Liébana-Cabanillas, F., \& Luna, J. G. de. (2017). NFC technology acceptance for mobile payments: A Brazilian Perspective. Review of Business Management, 19(63), 82-103. https://doi.org/10.7819/rbgn.v0i0.2315

Reith, R., Buck, C., Walther, D., Lis, B., \& Eymann, T. (2019). How Privacy Affects the Acceptance of Mobile Payment Solutions. 0-19. https://aisel.aisnet.org/ecis2019_rp/146

Rusydi Ananda, M. F. (2018). STATISTIKA PENDIDIKAN : Teori dan Praktik Dalam Pendidikan. In Journal of Visual Languages \& Computing, CV. WIDYA PUSPITA (Vol. 11, Issue 3).

Safitri, K. (2020). Per April, Jumlah Pengguna DANA Tembus 40 Juta User Per April 2020. $\quad$ Retrieved from https://money.kompas.com/read/2020/06/19/170609726/per-april-jumlahpengguna-dana-tembus-40-juta-user-per-april-2020

Saunders, M., Lewis, P., \& Thornhill, A. (2013). A playbook for Research Methods.

Shin, D. H. (2010). The effects of trust, security and privacy in social networking: A security-based approach to understand the pattern of adoption. Interacting with Computers, 22(5), 428-438. https://doi.org/10.1016/j.intcom.2010.05.001 
Singh, N., \& Sinha, N. (2020). How perceived trust mediates merchant's intention to use a mobile wallet technology. Journal of Retailing and Consumer Services, 52(March 2019), 101894. https://doi.org/10.1016/j.jretconser.2019.101894

Slade, E. L., Williams, M. D., \& Dwivedi, Y. K. (2016). Mobile payment adoption: Classification and review of the extant literature. Journal Customer Behaviour, 14(2), 127-146.

Soodan, V., \& Rana, A. (2020). Modeling customers' intention to use e-wallet in a developing nation: Extending UTAUT2 with security, privacy and savings. Journal of Electronic Commerce in Organizations, 18(1), 89-114. https://doi.org/10.4018/JECO.2020010105

Sugiyono. (2007). Statistika Untuk Penelitian (pp. 1-370). https://doi.org/10.1016/S0969-4765(04)00066-9

Suhartanto, D. (2020). Analisa Data untuk Riset Bisnis: SPSS, AMOS, PLS (2nd ed.). Politeknik Negeri Bandung.

Taylor, S., \& Todd, P. A. (1995). Understanding information technology usage: A test of competing models. Information Systems Research, 6(2), 144-176. https://doi.org/10.1287/isre.6.2.144

Teng, P. K., Ling, T. J., \& Seng, K. W. K. (2018). Understanding Customer Intention to Use Mobile Payment Services in Nanjing,China. International Journal of Community Development \& Management Studies, 2, 49-60. https://www.informingscience.org/Articles/v2p049-060Teng4446.pdf

Teo, A. C., Tan, G. W. H., Cheah, C. M., Ooi, K. B., \& Yew, K. T. (2012). Can the demographic and subjective norms influence the adoption of mobile banking? International Journal of Mobile Communications, 10(6), 578-597. https://doi.org/10.1504/IJMC.2012.049757

Tingari, W. M., \& Sanhori, M. M. (2016). Assessing the acceptance of mobile payment in sudan - using tam. International Journal of Engineering Sciences \& Research Technology, 5(2), 8-19. Retrieved from http://www.ijesrt.com/issues pdf file/Archive-2016/February-2016/2_ASSESSING THE ACCEPTANCE OF MOBILE PAYMENT IN SUDAN - USING TAM.pdf

Wong, W. H., \& Mo, W. Y. (2019). A Study of Consumer Intention of Mobile Payment in Hong Kong, Based on Perceived Risk, Perceived Trust, Perceived Security and Technological Acceptance Model. Journal of Advanced Management Science, 7(2), 33-38. https://doi.org/10.18178/joams.7.2.33-38

Yadav, P. (2020). ACTIVE DETERMINANTS FOR ADOPTION OF MOBILE WALLET. Authentic Assessment in Social Studies, 12(1), 85-95. https://doi.org/10.4324/9780429261114-6

Yang, Y., Liu, Y., Li, H., \& Yu, B. (2015). Understanding perceived risks in mobile payment acceptance. Industrial Management and Data Systems, 115(2), 253269. https://doi.org/10.1108/IMDS-08-2014-0243

Zhao, H., Anong, S. T., \& Zhang, L. (2019). Understanding the impact of financial incentives on NFC mobile payment adoption: An experimental analysis. International Journal of Bank Marketing, 37(5), 1296-1312. https://doi.org/10.1108/IJBM-08-2018-0229

Ziwei, F., Tham, J., Azam, S. M. F., \& Vocational, T. (2019). Determinants of Users' Willingness To Use Mobile Payment: an Empirical Study in Tongren Univerisity, China. European Journal of Management and Marketing Studies, 4(4), 16-38. https://doi.org/10.5281/zenodo.3560323 